\title{
Labour for Love or Love for Labour?
}

Shruti Sharma is a doctoral candidate with CSSSC, Kolkata. Her research interests include Critical geography and gendering of sports.

\section{I}

A woman at her workplace hallucinates about her son, daughter and husband asking "Mummy/Darling, aaj kya banega?" (Mummy/Darling, what will be cooked today?) She gets distressed and reaches home where she finds the children sitting in their school uniform with their father. Placing her office bag and files on a table anxiously she asks "Roz roz naya kya banau?" (What new things should I cook every day?) Her husband and son respond with a disinterested 'I do not know' shrug whereas her daughter sits with a blank face. The voice over of a man comes to her rescue and asks her family "Isliye Everest pesh karte hain arhtis masale, jisse bane roz naya...?" (That is why Everest presents to you thirty-eight types of spices, using which, every day what can be prepared...?) Her children and husband respond happily while eating the meal cooked by their mother and wife using Everest spices, "Tasty tasty khana" (Tasty tasty food). She can now prepare new and tasty dishes every day and be content about her children and husband being happy. The voice over ends with "Taste mein best, mummy aur Everest!" (The best when it comes to taste, mother and Everest!). ${ }^{1}$

A little girl has participated in 'Miss Snow White' competition for which she has to wear a white dress. Her mother is very excited and dances holding the dress her daughter is going to wear. She has a washing machine which washes whites keeping them pretty and the whitest, like it would have been if she would wash them herself. The technology of the machine is based on the 'magic' of the mother's hands which are capable of getting rid of the toughest stains, happily. The mother needn't be sceptical about the new technology as it has equal use value as her own labour power. "Uske har white mein hai magic haathon ka" (Every white has

${ }^{1}$ https:// www.youtube.com/watch?v=3dqdV-mqj7g, last accessed on 3 March 2020. 


\section{0 / Shruti Sharma}

Salesian Journal of Humanities and Social Sciences, Vol. X, No. 2 (Dec 2019)

ISSN: 0976-1861 | 10.51818/SJHSS.10.2019.129-141 | Page: 129-141,

Section: Articles

been washed with the magic of hands). While her husband and children sit and watch her dancing her way to the washing machine, a yellow spiral surfaces over the woman's head. Later we find out that the spiral is actually signifying a whirlpool, while the voice over adds - You and Whirlpool, the best homemakers". ${ }^{2}$ The background song and voice over are of men, again. ${ }^{3}$

The two descriptions that have been outlined above are of television commercials (hereafter, TVC) that are common to regular television viewers. In them, the wife/mother is the sole person doing housework - cooking new and tasty dishes every day, keeping clothes stainless and shining, keeping the house clean and germ-free corner to corner, to name a few. Doing housework is an activity that most women identify with at some point in their life. However, there is some uncertainty about whether women have been able to identify with the contentment and love that the onscreen actors portray while undertaking housework. Love is what she performs, tirelessly, happily and daily.

This paper seeks to 'burst asunder' ${ }^{4}$ this very notion of love into pieces that resemble the likes of Marxian concepts of labour power, use value, production, and alienation. With a brief contextualization of the isolationist accumulation of women within the household/private, the boundaries of the Marxian concepts have been pushed back to the period of their emergence as material processes, to the origin of family and the period of transition from feudalism to capitalism in Europe. Borrowing from Kalyan Sanyal, the central argument of the paper is that capital is not universal in its realization and it has to inherently depend on its supposed outside - the hetero patriarchal family - which is its invisibilized inside,

\footnotetext{
${ }^{2}$ Whirlpool did a series of television commercials with the same actors advertising its home appliances and the woman of the house as the 'best homemakers'.

${ }^{3}$ https:/ / www.youtube.com/watch?v=baI5XR6qVwI, last accessed on 3 March 2020.

${ }^{4}$ The phrase 'burst asunder' has been borrowed from Marx and Engels (1848)'s Manifesto of the Communist Party in which it has been used to denote the intensity with which developed productive forces became incompatible with the feudal relations of property and hence burst it asunder.
} 
where it accumulates surplus off the unwaged housework of women. ${ }^{5}$ Taking this as the node around which this paper revolves, it becomes essential to cater to two usual criticisms at the very outset - first, capital does not require labour in huge numbers as technological innovations have turned things around today and second, that women are not caged within their household anymore, they make the labour force in most nonadvanced capitalist countries as well. These criticisms emerge from the very view this essay aims to critique - the partial view that only looks at what happens in the public realm, in the realm of the 'productive' (mental and material) labour. With that aim in mind, we have to turn our lens towards what takes place within the four walls of a household.

The household has to be viewed not just as a site of reproduction of future generations through procreation or of labour power through everyday activities that are put under the rubric of 'love', but also as a site of production - the creative labour that turns raw materials into use value. Gender and sexuality cannot be treated solely as a cultural phenomenon but as work-function of capitalist class relations. ${ }^{6}$ This paper is a contribution to the everyday struggles of women which need to be brought out of their kitchens and bedrooms - from their isolation to the streets of solidarity and togetherness. This will enable us to view "women's history as class history."7

To begin the analysis of the concrete socio-economic conditions that wear the garb of 'love', we must go back to Friedrich Engels' (2004)The Origin of the Family, Private Property and the State (hereafter, Origin) in which he re-outlines the materialist conception of history as production and reproduction of immediate life being the determining factor, in the last resort. Production refers to the means of subsistence - of food, clothing, shelter and the tools required for it, and the propagation of species. The

${ }^{5}$ Sanyal, K., Rethinking Capitalist Development: Primitive Accumulation, Governmentality and Post-Colonial Capitalism, (New Delhi: Routledge, 2014).

${ }^{6}$ Federici, S., Wages Against Housework, (London: Falling Wall Press, 1975), 14.

7 Ibid. 


\section{2 / Shruti Sharma}

Salesian Journal of Humanities and Social Sciences, Vol. X, No. 2 (Dec 2019)

ISSN: 0976-1861 | 10.51818/SJHSS.10.2019.129-141 | Page: 129-141,

Section: Articles

former is defined as the stage of development of productive labour and the latter as that of the family. The social order seems to be determined by an inverse relationship between the two till the time society reaches a stage when the family system is dominated by the property system and the latter begins to predominate social existence. Engels' depicts the linearity from sexual promiscuity, group marriage, pairing family to the monogamous family as natural and evolutionary. This linearity is one from the mother right of inheritance to father right and from communal property to private property. Social and conscious history only begins at the institution of the monogamous family which is based on economic conditions before which Engels argues all forms of family under the institution of mother right had naturally evolved from one to another.

Critiquing Engels' selective application of historical materialism to the period he classifies as civilization and to the development of productive labour alone, Maria Mies (2014) argues for the extension of Marx's notion of 'appropriation of nature' to all of human history including savagery and barbarism, and to the development of family. She argues that in the German Ideology Marx and Engels leave out the 'third moment' that constitutes human life from the sphere of history. ${ }^{8}$ This third moment is that of the production of life - both of one's own labour and of fresh life in procreation. Dismissing the natural/evolutionary and social/historical binary which continues till today in the analysis of the development of family and of productive labour respectively, she asserts that if we have to follow Engels, we would have to conclude that "women have not yet entered history and still basically belong to the animal world." ${ }^{\prime 9}$

In the Origin, Engels' does state the production features of the 'prehistoric' period, which he terms as incontestable -the appropriation of ready to use natural products by instruments produced by mankind (savagery) followed by one in which the knowledge of cattle breeding and land cultivation was acquired which led to the increase in productivity of nature (barbarism). However, he does not view the ties of sex prevalent in

\footnotetext{
${ }^{8}$ Mies, M., Patriarchy and Capital Accumulation, (London: Zed Books,2014), 51.

${ }^{9}$ Ibid, 52.
} 
those periods through the samelens. Mies undertakes this task in Patriarchy and Capital Accumulation. She locates women in the abstract narrative of 'man the hunter' of the primitive stages by recognizing the appropriation of body as a productive force and the appropriation of nature by men and women distinctly. "The warrior-hunters lived in an economic system based on women's productive agricultural work; they were the husbands of female agriculturists"10 who would provide for daily subsistence irrespective of the men's success at hunting. Mies further distinguishes the former as the predatory/parasitic means of acquisition and the latter as the reciprocal/productive means of subsistence.

Apart from their hands or heads, women can experience their whole body as being productive. ${ }^{11}$ Out of their body they produce new children and food for them and also provide food for themselves daily as gatherers or agriculturists. The first sexual division of labour occurred between the daily activity of gathering means of subsistence by women and the sporadic hunting of men. The former was always a collective activity of the women folk. The everyday experience with plant life eventually led to the invention of regular cultivation of tubers and grains with the help of the digging stick and the hoe, tools invented by women. ${ }^{12}$ With the increase in productivity, the technological innovation for collection of surplus (storage containers) came to the fore. Along with these activities, it can be concluded that women were also the inventors of the first social relations - that between mothers and children. ${ }^{13}$

This point can be stressed further by placing it in tandem with Engels' (2004) incontestable features of prehistoric production - the mother right and communal ownership of property by the gens. Activities like gathering, cultivation and storing were the primary means of subsistence, the basic source of survival for mankind, in the period of savagery. The products that were gathered, cultivated and stored were done so by

\footnotetext{
${ }^{10}$ Ibid, 64.

${ }^{11} \mathrm{Ibid}, 53$

${ }^{12}$ Ibid, 55.

${ }^{13}$ Ibid, 56.
} 


\section{4 / Shruti Sharma}

Salesian Journal of Humanities and Social Sciences, Vol. X, No. 2 (Dec 2019)

ISSN: 0976-1861 | 10.51818/SJHSS.10.2019.129-141 | Page: 129-141,

Section: Articles

women folk in, from and for common. However, with the domestication/ breeding of animals and the invention of the plough (which Mies calls the symbol of the phallus, a tool to sow seeds into the field) social relations changed drastically as surplus beyond subsistence became available. ${ }^{14}$ Until the lower stage of barbarism, fixed wealth consisted mainly of the house, clothing, crude ornaments and instruments of procuring and preparing food which belonged to the gens. With herds of cattle, pastoralists acquired possessions demanding only supervision and elementary care in order to increase their number. ${ }^{15}$ The relationship of dominance between men and women was established when the former acquired knowledge about their generative capacities by observing the sexual behaviour of the domesticated cattle. ${ }^{16}$ With the requirement of more labour power for land cultivation (increase in territory) and to tend the cattle, slavery was invented and slaves were converted into family possessions. ${ }^{17}$ The patriarchal line of descent and inheritance were a consequence of this new mode of production.

Who would own this surplus which was way beyond the subsistence need? Those who had the monopoly of arms (man the hunter) to acquire labour power and surplus produce through predatory means. The natural father in the pairing family thus overthrew the mother right in favour of private ownership of property to be inherited by his children. The expropriation of women from their communal possessions and their bodies, thus the "world historic defeat of the female sex" led to the institution of the monogamous patriarchal family. ${ }^{18}$ The woman was reduced to being a slave of man's lust, a mere instrument for breeding children as the man seized the reins of the house. The fidelity of the wife was instituted to ensure undisputed paternity completing the "first class oppression in

${ }^{14} \mathrm{Ibid}, 57$.

${ }^{15}$ Engels, F., The Origin of the Family, Private Property and the State, (Australia: Resistance Books, 2004), 64 .

${ }^{16}$ Mies, 63.

${ }^{17}$ Engels, 65.

18 "The word familia did not originally signify the ideal of our modern Philistine, which is a compound of sentimentality and domestic discord...Familia signifies the totality of slaves belonging to one individual" (Engels, 67). 
history" - of the female sex by the male sex. ${ }^{19}$

In the brief history of sexual division of labour derived from reading Mies' critical engagement with Engels' Origin, we can conclude that women's activity of bearing and rearing children has been a conscious and social one. When it is interpreted as purely physiological, it reflects the ideological foundations of patriarchal and capitalist division of labour and not its precondition. However, we must be cautious of not reducing women solely to their capability to produce new life as irresponsible emphasis on it could makes us fall into the trap, we are critiquing, of biological determinism. At the same time, we need to equip ourselves with the ability to use the master's tools against them.

Bringing in Silvia Federici (2004)'s retelling of the history of transition from feudalism to capitalism in the Caliban and the Witch (hereafter, Caliban) is relevant here. Reworking Marx's conception of primitive accumulation, and Foucault's analysis of the power techniques to which the body was subjected, she situates women's reproductive labour in the continuous primitive accumulation of capital by highlighting the repressive character of power and the disciplinary techniques (witchhunts) used by the ruling class, to gain control over women's sexuality. This led to the gendered accumulation of their bodies in the household for the purpose of reproduction of labour. From the standpoint of women, the transition and movement of history through material dialectics doesn't seem progressive or liberative as Marx claimed it to be.

In Caliban, Federici traces the changes in the social position of women from the feudal order through the everyday peasant revolts and the heretic movement to the first phase of capitalism. She argues that the shortage of labour following the Black Death gave unprecedented power and unity to the working class. Threatened, the ruling class in Europe devised a multipronged policy for the accumulation of labour. The Conquest of Americas and successive Enclosures were complemented by controlling reproductive power of women through legislation and mass propaganda against deviants (demonization of witches) which led ${ }^{19}$ Engels, 73. 


\section{6 / Shruti Sharma}

Salesian Journal of Humanities and Social Sciences, Vol. X, No. 2 (Dec 2019)

ISSN: 0976-1861 | 10.51818/SJHSS.10.2019.129-141 | Page: 129-141,

Section: Articles

to the "accumulation of differences" 20 and divisions within the working class. The new social order was meant to relegate women to the sphere of the household by naturalizing their reproductive function leading to accumulation of unwaged work to provide for the social reproduction of the work-force free of cost. ${ }^{21}$ In the household, the accumulation of surplus value (unwaged housework which reproduces labour power) and the primitive accumulation (isolated accumulation of women) began taking place simultaneously yet invisibly.

The pertinent question remains - who were the witches?

The witches were the first practitioners of birth control and abortion; the midwives and wise women who possessed traditional knowledge; old widowed women or those who lived alone, negatively affected by land privatization as their families moved to the cities, leaving them to beg in the villages or rely on public assistance; the proletarian women who did not listen to their husbands; any women who did not identify herself with the normalized reproductive function that would benefit the capitalist work discipline. A witch is, therefore, any women who questions the passive norms of femininity slapped upon her, who is seen outside of her household, who doesn't want to or cannot bear a child, who doesn't do housework happily. A witch is the woman who questions the internalized voluntariness of housework as love, the necessary ideological mystification of their own self repression. And in writing this, I might as well be classified as a witch and so I call for a unity of the witches of the world...

${ }^{20}$ Federici, S., Caliban and the Witch, (Brooklyn: Autonomedia, 2004), 115.

${ }^{21}$ In the "Wages Against Housework" pamphlet, Federici (1975) contests the very nature of the naturalness of reproductive labour- "...it takes at least twenty years of socialisation - day-to day training, performed by an unwaged mother - to prepare a woman for this role, to convince her that children and husband are the best she can expect from life. Even so, it hardly succeeds" (p.3). 


\section{III}

They say it is love. We say it is un waged work.

They call it frigidity. We call it absenteeism.

Every miscarriage is a work accident.

Homosexuality and heterosexuality are both working conditions ...

but homosexuality is workers' control of production, not the end of work.

More smiles? More money. Nothing will be so powerful in destroying the healing virtues of a smile.

Neuroses, suicides, desexualisation: occupational diseases of the housewife.

(Federici, 1975, 1)

This section situates the household as a production unit and will unpack the notion of love. The wage that a worker receives in return of their expended labour time is exchanged for commodities in the market. These commodities are raw materials that need to be converted back into use value for the purpose of subsistence. The labour required to transform them into "articles of consumption" 22 and the affective labour that goes into reproducing labour power (the commodity that the worker is)as well as the bearing/rearing of children is the daily activity of (re)production undertaken by the women of the household. It does not matter who the wage earner is, women are naturally predisposed to doing this activity.

Unlike the 'public' workplace where the commodified worker is alienated from the activity of producing the object of alienation, from themselves and hence from their species character, the 'private' workplace is the site where women are not free to even feel this alienation. They are alienated from the experience of feeling alienated as the system mystifies housework as their species character. Reduced to producing and reproducing the 'animal functions' for the capitalist system, it is evident that women could have only accepted this role after a prolonged struggle with the parasitic and predatory non-producers. ${ }^{23}$

${ }^{22}$ Sanyal, 62.

${ }^{23}$ Mies, 57. 


\section{8 / Shruti Sharma}

Salesian Journal of Humanities and Social Sciences, Vol. X, No. 2 (Dec 2019)

ISSN: 0976-1861 | 10.51818/SJHSS.10.2019.129-141 | Page: 129-141,

Section: Articles

The norms of ideal femininity - being chaste (innocent, virtuous, faithful), passive (submissive, docile), obedient (dutiful and compliant), thrifty (economical), of few words, always busy at work (reproduction of the labour-force); covered by the necessary ideological mystification called love ensures that women smile and dance their way through this daily alienation.

It is essential to go back to the description of the two TVC's at the outset of the essay. In both the TVCs the protagonist is a woman who has a double work day - first in the private and second in the public. Even though women's employment in the public sphere is on the rise, their natural predisposition towards housework remains unshaken. The husband and children have barely any dialogues and respond to the woman (wife and mother) through shrugs, giggles or laughter. The audience that these two TVCs have in mind is the modern urban middle-class heterosexual nuclear family. This is clearly evident from the locational setup of the TVCs which means that only a certain section of the population can seek validation of their realities in it. It seems as if the TVC is telling its viewers that irrespective of your social location, your women have to do housework. Second, both the TVCs seem to be advertising two distinct elements - the wife/mother and the object she has to work with to convert its rawness into use value. And third, the background sound track is a happy and playful one. While watching the advertisement one can almost sway to the music. This makes the viewer feel that housework is not work but play adding to the evidence that capital invisibilizes women's labour in the household as a fun and love filled activity.

The two things that strike out instantly are, first, the happiness that the woman expresses while working (cooking new dishes every day and washing clothes) and second, the male expert voice over which explains the technicalities of the commodities in the TVCs. Ironically, it is not the man who is to use the spices or work with the washing machine. In the first TVC he is seen sitting idle with his children when the woman gets back to housework. She is distressed about providing tasty food daily to her family to such an extent that she cannot focus on work in office. The 
husband's disinterested shrug is a usual response to housework related questions in most households. However, another man comes to her rescue - the man who suggests Everest's range of thirty-eight spices using which she can prepare new and tasty dishes daily.

In the second TVC one does not realise what the commodity on advertisement is. We see the protagonist dancing happily around the house with a white satin dress (later we realise its her daughter's attire for 'Miss Snow White' competition). Her husband and children giggle and watch her. The voice over keeps repeating "Uske Har White Mein Hai Magic Haathon $\mathrm{Ka}^{\prime \prime}$. We know that the magic that is being sung about is that of the labour power of the woman. Her hands have the magic to get rid of stains from whites. This mystification of labour power, invisibilization of housework, is the basis of the accumulation of surplus value which is not catered for in the subsistence wage of the worker. The TVC equates the machine's efficiency (advanced hand wash agitator) with that the labour power of the woman also recognizing that machines would never be able to outdo the value of human labour.

The TVCs reinforce the oppressive social relations by representing the social conditions which are the basis of capital - the heteropatriarchal nuclear family and the naturalized, open yet disguised enslavement of women within the household. Capital needs to convince us through all possible means that housework comes naturally to women, is unavoidable and an activity full of love. This unwaged condition of housework has been the most powerful weapon in reinforcing the common assumption that housework is not work but love, preventing women from struggling against it. ${ }^{24}$

\section{IV}

Mies and Federici's critique of the orthodox Marxian discourse for overlooking the household also breaks the universality of capital. Labour power is not reproduced at the site of capitalist production but in the non-capitalist site of production - the household. The relationship

${ }^{24}$ Federici 1975, 2. 


\section{0 / Shruti Sharma}

Salesian Journal of Humanities and Social Sciences, Vol. X, No. 2 (Dec 2019)

ISSN: 0976-1861 | 10.51818/SJHSS.10.2019.129-141 | Page: 129-141,

Section: Articles

between capital and the household is one of extraction/appropriation, in which capital extracts the labour performed in the household in the form of reproduced labour power. ${ }^{25}$ The household is the intrinsic inside of capital which creates the economic conditions of capital's expanded reproduction and is also the site that challenges capital's political and ideological universality, unsettling the state of its being. ${ }^{26}$

Having traced the changes in the social valuation of the daily subsistence work done by women- from being the first institutors of social relations, the intrinsic providers of means of subsistence, the first gatherers of nature's produce and inventors of cultivation tools to the ones who have been enslaved within the household - reproducing labour power, bearing and rearing prospective labour power and transforming commodities purchased from wages into articles of consumption/use value -it can be concluded that the institution of the patriarchal monogamous family pushed women out of production to ensure undisputed paternity for the owners of property and to reproduce labour power for those who had only their labour power as property. The naturalness of this activity, as opposed to its conscious and social nature before the institution of the monogamous family, is reinforced through the notion of love, the ideological blanket over the appropriation of surplus (unwaged) labour.

In contemporary times, every act of primitive accumulation is accompanied by newer forms of patriarchy where women expropriated from the commons, are isolated in their households and made to reproduce labour power which has to follow the capitalist work discipline. One may argue that technological innovations have altered social relations. These affect a miniscule percentage of the population who can afford them. However, even for this section, housework, irrespective of the level of technology and freedom is to be undertaken by women. It may be just switching the machine on, or the transfer of child rearing activity to the mother in-law or a nanny, it is nonetheless women whose natural predisposition remains reinforced. Women are the sole repositories of

${ }^{25}$ Sanyal, 62-3.

26 Ibid, 64. 

ISSN: 0976-1861 | 10.51818/SJHSS.10.2019.129-141 | Page: 129-141, Section: Articles

love and the most elementary form of its expression is housework. Can women be loved if they do not labour at home? Can women define love without any reference to labouring at home? 